\title{
Assessment of Prevalence of Road Traffic Accident and it's Associated Factors in Chuko Town, Southern Ethiopia
}

\author{
Kaleab Tesfaye Tegegne (BSCPH, MPH)* \\ Department of Public Health, Hawassa College Of Health Science, Hawassa, Ethiopia
}

\section{*Corresponding Author}

Kaleab Tesfaye Tegegne

\author{
Article History \\ Received: 14.11.2019 \\ Accepted: 21.11.2019 \\ Published: 30.11 .2019
}

\begin{abstract}
Background: A road traffic accident is an incident on a way or street open to public traffic, resulting in one or more persons being killed or injured, and involving at least one moving vehicle..Ethiopia, a developing country in Africa, has witnessed a number of the most risky roads in the world and has followed to overtake a determined road spreading out guiding principle in the past 15 years. Objective: To assess the prevalence and associated factors of Road Traffic Accidents in Chuko town, Sidama zone, Southern Ethiopia from March 27 to April 4, 2009 E.C. Method: Community based cross sectional study was done in Chuko Town with a total sample size of 422 from March 27 to April 4, 2009 E.C. The quantitative data was checked, edited, and entered to SPSS software version 20. The study employed logistic regression and chi-square analysis models. Data from qualitative was analyzed manually then triangulated with the quantitative one. The result is presented using descriptive statistics using tables, graphs and charts. Result: A total of 422 respondents participated in our study with 100\% respondent rate. Among them, 244 (57.8\%) were male and the rest $178(42.2 \%)$ were female. Among the participants recruited on data collection, $99(23.5 \%)$ of them had previous history of RTA. Concerning the causes of RTA, 141(33.4\%) majority of them were caused by poor road condition followed by $119(28.2 \%)$ by over speed. The results from FGDs and interviews showed that the Town has traffic flow and motor bikes were most common causes of the accident. It also revealed that the Road and Traffic Office had worked on public education even if it's not enough. Conclusion and Recommendation: The study found out that RTA is big problem of the Town and the Town is experiencing it. The most common cause of RTA is poor road condition and Motor Bikes are most commonly involved in the accident. Legalizing Motor Bikes, public meeting and improving the road condition are among the recommendations given to various groups.
\end{abstract}

Keywords: Road traffic accidents, motor vehicle accidents, overspeed.

\section{INTRODUCTION}

Road traffic injuries are a serious public health problem worldwide [10]. Road traffic injuries (RTIs) are a significant public health challenge and projected to be the fifth leading contributor to the global burden of disease by 2030 [11]. Road deaths and injuries are preventable. They are one of the leading causes of premature deaths, hospitalizations, disabilities, and socioeconomic losses.RTA ranks as the $11^{\text {th }}$ leading cause of death and accounts for $2.1 \%$ of all deaths globally. The most vulnerable road users are pedestrians, cyclists, two-wheeler riders, and passengers on public transport RTA deaths are predicted to increase by $83 \%$ in developing countries and to decrease by $27 \%$ in the developed countries. It is estimated that every year RTA costs billions of rupees globally and nationally. An RTA injury puts significant strain on health care budgets [12].

In Ethiopia, the situation has been worsened as the number of vehicles has increased consequently due to increased traffic flow and conflicts between vehicles and pedestrians [14]. Despite government efforts in the road development, road crashes remain to be one of the critical problems of the road transport sector in Ethiopia [15]. Every year, many lives are lost and huge property is destroyed due to road traffic accidents in the country. The Country has experienced average annual road accidents of 8115 over the past 11 years [16]. In financial terms, Ethiopia, one of the poorest countries in the world, looses at least 400 million Birr each year due to road accidents, which was 12 million Birr per year on average, 15 years ago and was the third killing vector [17]. Currently, the financial estimation of property damage (excluding human deaths and injuries), is more than 15 million Ethiopian birr annually on average [16]. According to UNECA (2009), the rate of traffic accident death in 2007/08 was 95 per 10,000 motor vehicles, which put

Copyright @ 2019: This is an open-access article distributed under the terms of the Creative Commons Attribution license which permits unrestricted use, distribution, and reproduction in any medium for non commercial use (NonCommercial, or CC-BY-NC) provided the original author and source are credited. 
the country on the extreme high side of the international road safety scene. Moreover, in the same year, the police report revealed that 15,086 accidents caused the loses of 2,161 lives, and over 82 million Birr, equivalent to US $\$ 7.3$ million estimated cost of property damaged. (US $\$ 1=11.34$ Ethiopian Birr).Also, up to 2005/06, traffic accidents and fatalities increased at $17 \%$ and $10 \%$ per year respectively although there is a decreasing trend in this respect. There were 2.84 road accident fatalities per 100,000 populations in the same year [15].

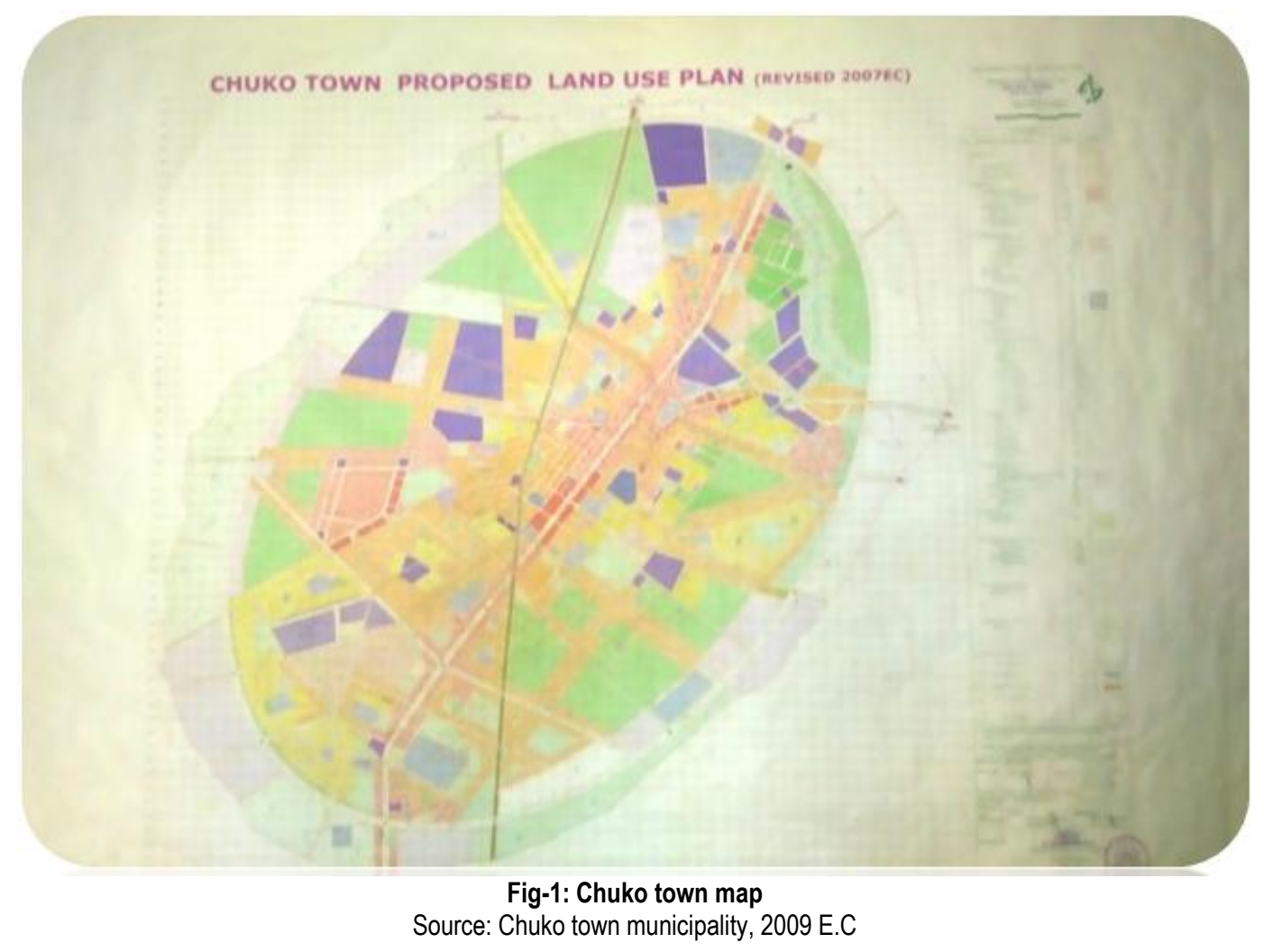

Therefore, understanding of road traffic accidents and identifying black spots has paramount importance to implement remedial solution for these severer problems. In light of these, in this research it is tried to assess and avail information on road traffic accidents and black spots of the sidama zone of south Ethiopia particularly Chiko town administration.

\section{Subjects and Methods \\ Study Area and Period}

This research was conducted in Sidama zone, Chuko Town, south Ethiopia. SNNPR has 13 zones, 508 special weredas and from these Sidama is the one and it spreads out in a cone shaped area of the middle of southern Ethiopia. The Zone is bordered by Arsi Oromo in the North, and West, Gedeo, Burji and Guji Oromo in the South, Guji Oromo in the West and Wolayita and Kambatta in the East. It has geographic coordinates of latitude, North: 5'45" and 6'45" and longitude, East: 38' and 39'.Chuko town is located 76 kms from Hawassa, the capital of the region. The town has 22,953 populations, 11,252 males and 11,701 females.

The study was conducted from March 27-April 4, 2009E.C.

Study Design: Community based cross sectional study design was used.

\section{Study Population}

All individuals selected by systematic sampling method, some selected government officials and traffic police

\section{InCLUSION ANd ExCLUSION CRITERIA Inclusion Criteria}

- $\quad$ The respondent within the age of 18 and above.

- $\quad$ People who live in the study area for six month and above.

- Willing to Participate 


\section{Exclusion Criteria}

- Who have hearing and speaking problem.

- Those who are severely ill and those who has psychiatric problems.

\section{Sample Size and Sampling Technique}

The sample size was calculated using single proportion formula as:

$$
\mathrm{n}=\frac{z^{2}(p)(1-p)}{w^{2}}
$$

We took the confidence interval $95 \%$, so the $Z$ value $=1.96$, and margin of error $(W)=0.05$.

We took $P$ value 0.5 since there is no study done in this locality or other place where the socioeconomic status is similar to Chuko town.So the sample size was calculated as follow:-

$$
\mathrm{n}=\frac{1.96^{2}(0.5)(1-0.5)}{0.05^{2}}=384
$$

Where,

Z=confidence interval

$\mathrm{N}=$ total population

$\mathrm{n}=$ sample size

$\mathrm{W}=$ margin of error

$\mathrm{P}=$ proportion of population in success in the previous study Adding $10 \%$ non-respondent rate, the final sample size was 422.

One kebele was selected randomly by lottery method from the two kebeles and the households were selected by systematic sampling technique. Each house hold was selected by the constant value $\mathrm{K}$ that will be obtained as follow:

$$
\mathrm{K}=\frac{N}{n}=\frac{5646}{422}=13
$$

So each household was recruited within the interval of 13 households. The first household was selected randomly by lottery method from the first 13 households. For qualitative data, the sampling technique was convenient sampling where some stakeholders were selected purposively

\section{Data Collection Procedures}

The study used semi structured questionnaire for the qualitative results and structured for that of quantitative study. The questionnaire was adopted from similar studies and modified according to the study context. About 3 Focused Group Discussions were held each of them containing 8-12 members. In-depth interview was done with the head of Roads and Transport Office of Chuko town. Secondary data was obtained from Roads and Transport office

Data was collected by public health students. The students were divided in to groups in order to collect the data from different groups and the community.

\section{Data Quality Assurance}

Quality of data assured through pretesting of the questionnaire on $5 \%$ of population Data was collected by trained interviewers who are public health students The interviewers conducted the structured interviews under the supervision of the investigator. Every day $5 \%$ of the questionnaire was randomly selected and checked for completeness and consistencies. In addition meetings have been held to discuss the problems if any before the data collectors go back to their home

\section{Data Processing and Analysis}

The quantitative data was checked, edited, and entered to SPSS software version 20. The study also employed chi-square analysis models. Data from qualitative was analyzed manually then triangulated with the quantitative one. The result was presented using descriptive statistics using tables, graphs and charts.

\section{Operational Definition}

Accident casualty - refers to road crash victims, which include injuries and fatalities.

Accident Frequency - is a measure of the relative magnitude of a specific type of accident in relation to all accidents for a specified time period such as one or three years.

Accident Rate - is a measure of the rate of occurrence of accidents in relation to time for example, 10 accidents per year. 
Fatal Accident - is one where at least one person is killed with death occurring within 30 days of the accident.

Property Damage - Physical damages of vehicles or properties but not to a person

Road Traffic Accident - is defined as a rare, random and multiple factor events always preceded by a situation in which one or more road users have failed to cope with the road and its environment.

Severe injury- At least one person was injured and admitted in hospital, but no deaths occurred.

Slight injury- At least one person required medical care, but no fatalities or injuries that required hospitalization occurred.

Traffic Accident -Are any vehicle accidents occurring on public high way (i.e. originating on, terminating on, or involving a vehicle partially.

\section{Ethical Considerations}

Ethical support letter was obtained from Rift Valley University Hawassa Campus Ethical review board Confidentiality was maintained through not writing the name of the respondents. The respondents were asked with oral informed consent for their willingness and was made free to decide whether to participate or not.

\section{RESULTS}

\section{Socio Demographic Characteristics of the Respondents}

A total of 422 respondents participated in our study with $100 \%$ respondent rate. Among them, 244 (57.8\%) were male and the rest $178(42.2 \%)$ were female. The age of the respondents range from 18 to 66 and the mean and standard deviation of their age were 31.66 and 10.12 respectively. Majority of the respondents, 157 out of $422(37.2 \%)$ attended only primary school, 144(34.1\%) up to secondary school, $78(18.5 \%)$ above grade 12 and small amount of them, $43(10.2 \%)$ had no formal education. $125(29.6 \%)$ of the respondents were merchants whereas $78(18.5 \%), 77(18.2 \%), 53(12.6 \%), 39(9.2 \%)$ were Students, private workers, office workers and unemployed respectively and $50(11.8 \%)$ had other occupations.

Table-1: Socio demographic characteristics of the respondents, Chuko town, 2009 e.c

\begin{tabular}{|l|l|l|l|}
\hline Variable & \multicolumn{2}{|c|}{ Frequency } & Percent \\
\hline \multirow{5}{*}{ Age } & $18-30$ & 245 & 58.0 \\
\cline { 2 - 4 } & $31-42$ & 113 & 26.8 \\
\cline { 2 - 4 } & $43-55$ & 53 & 12.6 \\
\cline { 2 - 4 } & $\geq 56$ & 11 & 2.6 \\
\cline { 2 - 4 } & Total & 422 & 100 \\
\hline \multirow{5}{*}{ Occupation } & Male & 244 & 57.8 \\
\cline { 2 - 4 } & Female & 178 & 42.2 \\
\cline { 2 - 4 } & Total & 422 & 100 \\
\hline & Private worker & 77 & 18.2 \\
\cline { 2 - 4 } & Unemployed & 39 & 9.2 \\
\cline { 2 - 4 } & Student & 78 & 18.5 \\
\cline { 2 - 4 } & Office worker & 58 & 12.6 \\
\cline { 2 - 4 } & Merchant & 125 & 29.6 \\
\cline { 2 - 4 } & Other & 50 & 11.8 \\
\cline { 2 - 4 } & Total & 422 & 100 \\
\hline Educational level & No formal education & 43 & 10.2 \\
\cline { 2 - 4 } & Only primary school & 157 & 37.2 \\
\cline { 2 - 4 } & Up to secondary school & 144 & 34.1 \\
\cline { 2 - 4 } & Above grade 12 & 78 & 18.5 \\
\cline { 2 - 4 } & Total & 422 & 100 \\
\hline
\end{tabular}

\section{Causes of RTA in the Town}

Concerning the causes of RTA, $141(33.4 \%)$ majority of them were caused by poor road condition, $119(28.2 \%)$ by over speed, $50(11.8 \%)$ by number of vehicles, $33(7.8 \%)$ by lack of drivers experience, $23(5.5 \%)$ by not giving priority to pedestrian and $22(5.2 \%)$ by driving while getting drunk. But according to FGD done with Road and Transport office workers, the most common cause is lack of awareness of the community. 


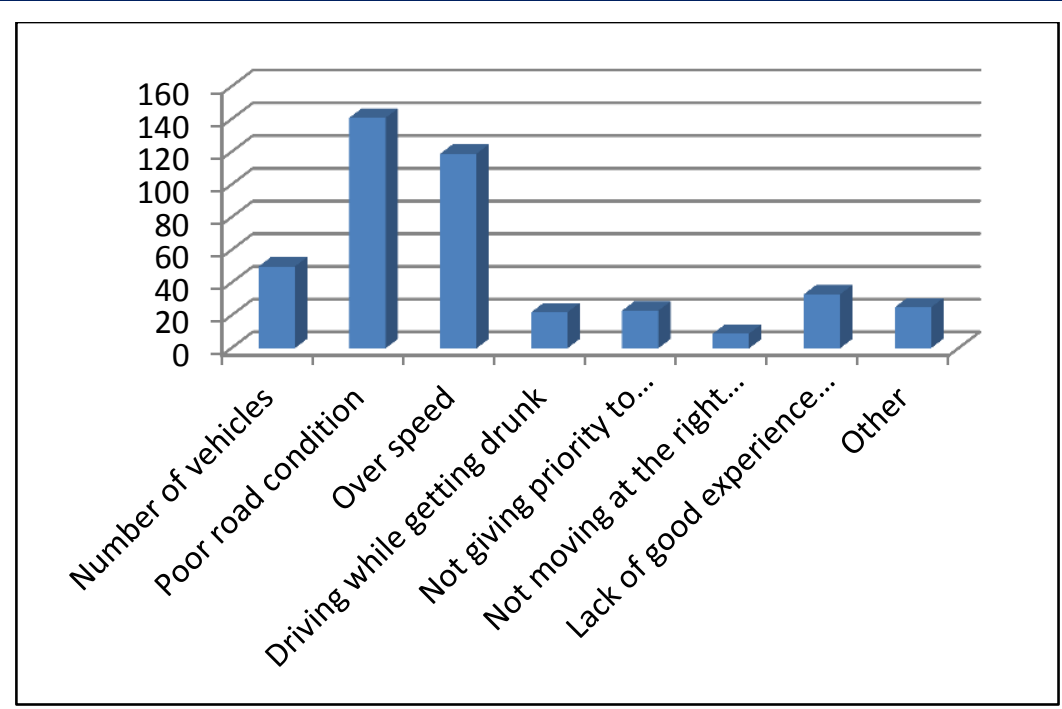

Fig-2: Graph showing the causes of RTA in Chuko town, 2009 e.c

On the basis of the Town's experience of RTA, 369 out of the 422 respondents (87.4\%) responded that Chuko Town is a town experiencing RTA and the rest 53(12.6\%) didn't. Regarding the place of crossing roads, $248(58.8 \%)$ of the respondents cross road at any point, $91(21.6 \%)$ cross at junction and $83(19.7 \%)$ of them cross at mid-block. $366(86.7 \%)$ of the respondents thought that lack of traffic signs and behavior of pedestrian can be cause of RTA.

Regarding the difficulty of crossing the main road of the Town, $220(52.1 \%)$ responded that it's very difficult to cross it, 95(22.5\%) said difficult, $77(18.2 \%)$ less difficult and 25(5.9\%) replied it was easy. Concerning the sources of knowledge, 142(33.6\%) of them got from media, 103(24.4\%) from schools, 92(21.8\%) from themselves, 66(15.6\%) from traffic polices and the rest $9(2.1) \mathrm{got}$ from their parents.

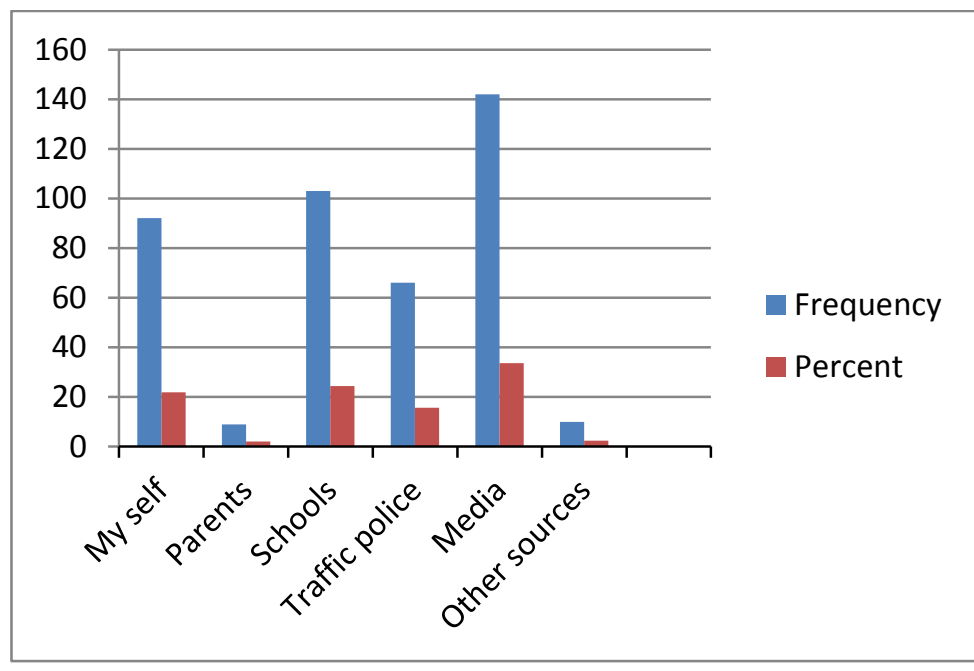

Fig-3: Graph showing the source of knowledge about road safety rules of the respondents in Chuko town, 2009 e.c

On the basis of commitment of traffic polices to their duties, $189(44.8 \%)$ of the respondents disagreed, 150(35.5\%) agreed, $40(9.5 \%)$ said indifferent, $25(5.9 \%)$ strongly disagreed and small amount of the respondents $18(4.3 \%)$ strongly agreed. Regarding the use of roads, $270(64.0 \%)$ of them used to travel facing to oncoming vehicle, $95(22.5 \%)$ of them used to travel while the oncoming vehicle comes from their back and the rest $57(13.5 \%)$ used to travel on both ways while they are traveling on the main road.

Table-2: Respondent's perception regarding the level of RTA in Chuko town, 2009 e.c

\begin{tabular}{|l|l|l|l|}
\hline Respondent's Perception & Frequency & Cumulative freq. & Per cent \\
\hline Big problem & 262 & 262 & 62.1 \\
\hline Moderate problem & 144 & 406 & 34.1 \\
\hline Not a problem & 16 & 422 & 3.8 \\
\hline Total & 422 & & 100.0 \\
\hline
\end{tabular}


Among the participants, $287(68.0 \%)$ of them perceives Traffic signs, signals and road marks while they are moving on the streets and crossing the road, while the rest 135(32.0\%) don't.

\section{Level and prevalence of RTA in the Town}

Among the participants recruited on data collection, 323(76.5\%) of them had no previous history of RTA, while the rest $99(23.5 \%)$ of them had previous history of RTA Concerning the mode of transportation of the participants, $204(48.3 \%)$ of them mostly uses Motor Cycle as a mode of transportation, while 160(37.9\%) of them were pedestrians, 25(5.9\%) use 'Bajaj' and 33(7.8\%) private car.

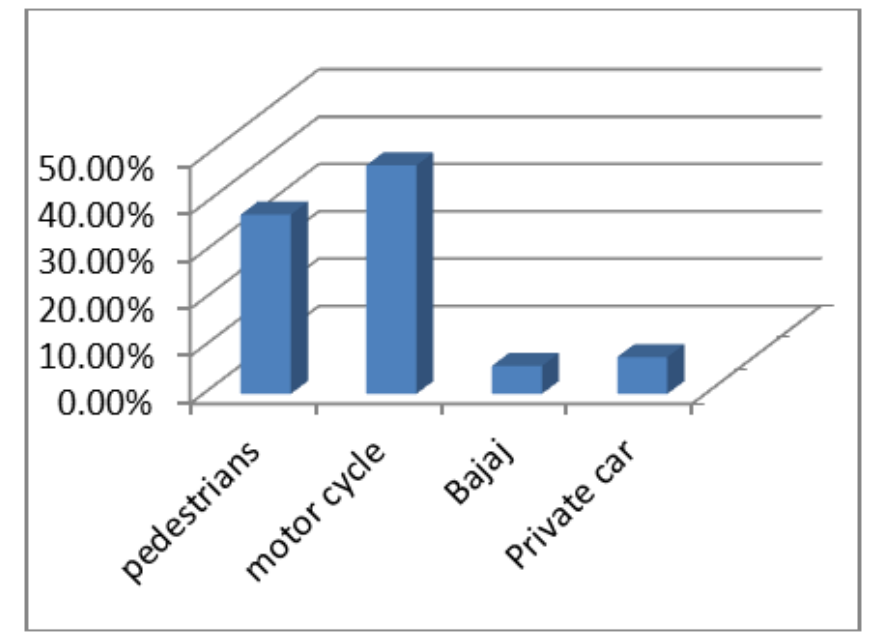

Fig-4: Graph showing the mode of transportation in Chuko town, 2009 e.c

On the basis of drivers giving priority to pedestrians, $175(41.5 \%)$ of them believed as drivers poorly gives priority to pedestrians as required by law, while $146(34.6 \%)$ believed that it was very poor and the rest believed that it was good $(64(15.2 \%))$, very good $(25(5.9 \%))$ and excellent $(12(2.8 \%))$.

In case of punishment given to drivers who fail to maintain traffic rules and regulations, $271(64.2 \%)$ of them believed that drivers who failed to maintain traffic rules and regulations in the presence of traffic police sometimes get penalized according to their law effectively, $91(21.6 \%)$ of them believed that they always get penalized while the rest $60(14.2 \%)$ believed that they never got penalized

On the behalf of education by concerned officials about road safety rules, 259(61.4) of them had never got education about by concerned officials while the rest $163(38.6 \%)$ had got the education.

Regarding the solutions sought by the respondents for the problem, 187(44.3\%) of them believed that the solution for the existing RTA is Creating awareness on the society, 107(25.3\%) of them believed that it is by repairing the road and increasing the road capacity, while the rest puts making rules and regulation(26(6.1\%)), punishing those who disobey the rules and regulations $(25(5.9 \%)$, reducing corruption $(17(4.0 \%))$, limiting and controlling the speeds of vehicles $(15(3.6 \%))$, giving priority for pedestrians $(9(2.1 \%))$, planting and assigning traffic signs in the streets $(7(1.7 \%))$, giving identification number for vehicles $(6(1.4 \%))$, cooperation with traffic polices $(6(1.4 \%))$, avoiding alcohol while driving $(6(1.4 \%))$, Reducing the number and types of vehicles $(3(0.7 \%))$ and qualifying the drivers well and restricting those who drive without licenses $(2(0.5 \%))$.

Results from chi-square showed that age and RTA had positive association at $p<0.05(0.01)$ taking $95 \%$ confidence interval.in Chuko town, 2009 e.c.

Table-3: Chi-Square Tests

\begin{tabular}{|l|l|l|l|}
\hline & Value & Df & Asymp. Sig. (2-sided) \\
\hline Pearson Chi-Square & $68.675^{\mathrm{a}}$ & 42 & .006 \\
\hline Likelihood Ratio & 77.271 & 42 & .001 \\
\hline N of Valid Cases & 422 & & \\
\hline
\end{tabular}

\section{FGD DONE WITH ROAD AND TRAFFIC OFFICE WORKERS}

Date 04/08/09 time 4:30-5:30 place Snake house

According to Road and Traffic police members, Chuko town is an area of cash crop product due to this reason mostly the community use many type of transportation system, especially motor bicycle, Bajaj, Minibus and Isuzu to move place to place. 
Chuko town has four entry and exit roads: those are from Chuko to Hawasa, Chuko to Dilla, Chuko to AlataWondo and Chuko to Nekebas.

RTA in Chuko town mostly occurs due to the following reason:

1. Lack of awareness about RTA among the community

2. Lack of experience and negligence of the drivers.

3. Poor road conditions

4. Over speed.

\section{Focused group discussion in Chuko health center}

A total of 10 people participated in the group discussion as they said that they perceived transportation in Chuko town ;it is illegible with regarding a number of condition such as: number of people who load on motor more than the acceptable ,also traffic police is not take responsibility correctly.

They also said that magnitude of road traffic accident is increase day to day, especially motor vehicle accident. Male adolescents are the most victim for the accident., as they stated the common cause for RTA are :over speed while driving, lack of experience of drivers, driving while getting drunk and poor road condition. Finally, they put idea what should be done for the future:

Address coverage of education for the whole community

Work together with government

Give priority for road construction rather than other infrastructure

The traffic police should take their responsibility

Focus group discussion with student traffic police

Majority of participant perceive that there was a great traffic flow in Chuko town since the town is the center of different cash crop.

The causes as listed by the students were:

- Over speed of motor cycles

- Poor road construction

- Transporting more than two passenger in a single motor cycle and

- Lack of experience of the driver and soon

The interventions done to alleviate the problem of road traffic accidents were like:

- $\quad$ Educating the community in creating awareness on RTA

- Penalizing drivers who go beyond the rules and regulations of road traffic and

- Participating students as student traffic

\section{Interview with Road and transport office}

The most common RTA in the town is motor vehicle accident (MVA). Many of the MVA are not reported all the time to road and transport office so that the total number of accidents are not well known.

\section{Secondary data from Chuko Police Office}

Secondary data from Chuko police office regarding RTA in the town showed that there were 2 deaths 3 severe physical injury and 6 no severe physical injury by the year 2008 E.C. Where as in this year (2009E.C), the six month report indicates that there were 3 deaths, 2 severe physical injuries and another 2 non-severe physical injury had been registered.

\section{Discussion AND CONCLUSION}

This study was conducted with the aim of assessment of prevalence of RTA in Chuko Town and its associated factors. This study has found out that, RTA is big problem of the Town, 262(62.1\%) of the respondents responded as its big problem. This number is slightly higher than a study done in Bahir Dar (51\%) [30]. this may be due to poor road condition of Chuko Town when compared to Bahir Dar.

This study has found that poor road condition is the most common cause of RTA (33.4\%), but according to research done in Addis Ababa; it was found that Failure to give way for pedestrians is most common cause of RTA (53.8\%) [12].

This may be due to absence of good pavement in Chuko Town which is moreover 'pista' with ups and downs snatching flood when raining and has no "zebra" for crossing the road, no traffic lights and signs, no way for pedestrian and only a single lane. 
But according to research done in Bahir Dar, the most common cause of RTA was found to be driver's error [30]. This is probably for the reason that failure to give priority to pedestrians was high in Bahir Dar (10.7\%).

Regarding perception of traffic signs, in this study, only $32(36 \%)$ of all pedestrians indicated, as they perfectly understood traffic signs, but in our study it was $68 \%$ and this may be due to good education given by traffic polices and concerned officials.

According to this study, $175(41.5 \%)$ of the respondents believed as drivers poorly gives priority to pedestrians as required by law, this number is comparable with study done in Addis Ababa which showed 41(41 percent) of drivers do not give priority to pedestrians [32]. This is probably due to negligence of the rules and regulation of drivers.

The study also showed that $150(35.5 \%)$ respondents agreed that traffic polices are committed to their job and when this is compared to the above study done in Addis Ababa, it was found to be higher (20\%) and this may be due to good coordination of the traffic polices with themselves and the community.

In conclusion, the prevalence of RTA was found to be high. The result from chi square analysis showed that there is positive association between age and prevalence of RTA. The study also revealed that:

- $\quad$ RTA is big problem of the Town and the Town is experiencing it.

- $\quad$ 'The most common mode of transportation is motor cycle.

- Majority of the participants perceive traffic signs.

- The most common cause of RTA is poor road condition and Motor Bikes are most commonly involved in the accident.

- It's very difficult to cross the main road

\section{AbBreVIATIONS AND ACRONYM}

$\begin{array}{ll}\text { AAU } & \text { Addis Ababa University } \\ \text { CSA } & \text { Central Statistical Agency } \\ \text { E.C } & \text { Ethiopian Calendar } \\ \text { MVA } & \text { Motor Vehicle Accident } \\ \text { RTA } & \text { Road Traffic Accidents } \\ \text { RTIS } & \text { Road Traffic Injuries } \\ \text { UNECA } & \text { United Nations Economic Commission for Africa } \\ \text { US } & \text { United States } \\ \text { WHO } & \text { World Health Organization }\end{array}$

\section{ACKNOWLEDGMENT}

I would like to express my gratitude to data collectors and community of cheko town for their unreserved help and facilitation.

My heartfelt thanks also goes to Rift Valley University Hawassa Campus for giving me this chance for practicing this Research work. Finally, I am greatly indebted to my Wife Netsanet Desalegne who gave me courage deserves my utmost gratitude for helping me to do this Research work

\section{REFERENCES}

1. American public health association. (2001). Transportation and Public Health, Washington, DC.

2. Dandona, R., \& Mishra, A. (2004). Deaths due to road traffic crashes in Hyderabad city in India: need for strengthening surveillance. National Medical Journal of India, 17, 74-79.

3. Ameratunga, S., Hijar, M., \& Norton, R. (2011). Road-traffic injuries: Confronting disparities to address a global-health problem.

4. Nantulya, V. M., \& Reich, M. R. (2011). The neglected epidemic: Road traffic injuries in developing countries.

5. Peden, M. (2004). World Report on Road Traffic Injury Prevention. Geneva, Switzerland: World Health Organization.

6. World Population Prospects. (2003). The 2002 Revision Comprehensive Tables. New York, NY, USA: United Nations.

7. Odero, W., Garner, P., \& Zwi, A. (1997). Road traffic injuries in developing countries: a comprehensive review of epidemiological studies. Tropical Medicine \& International Health, 2(5), 445-460.

8. WHO (World Health Organization). (2009). Global Status Report on RoadSafety: Time for Action. Geneva: http://www.un.org/ar/roadsafety/pdf/roadsafetyreport.pdf [accessed 20 September 2013]

9. Elas, A. (2005). Tezzerachaka, the pattern of orthopedic. Ethiopia medical Journal, 43:85-91.

10. WHO: (2009). Global status report on road safety: time for action. Geneva: World Health Organization.

11. Mathers CD, Loncar D: Projections of global mortality and burden of disease from 2002 to 2030. PLoS Med 2006, 3(11):e442.

12. AntenehKebedeSebsbie BSN, Road Traffic Accident related Fatalities in Addis Ababa City, Ethiopia: An Analysis of Police Report 2013/14

13. Asaye, Y. (2015). The Causes of Road Traffic Accidents in Bahir Dar City, Ethiopia. 
14. Guyu, F. (2011). The Development of Bullen Town in Benishangul-gumuz Regional State ofEthiopia: From Historical, Socioeconomic and Institutional Perspectives; VDM Verlag Publication, Germany.

15. United Nations Economic Commission for Africa (UNECA). (2009). Case Study: Road Safety in Ethiopia, Unite Nations Economic Commission for Africa Report.

16. 'Central Statistical Agency (CSA). (2000-2012). Summary and Statistical Report of the 2007Population and Housing Census Results, Addis Ababa, Ethiopia.

17. Fanueal, S. (2006). Analysis of Traffic Accident in Addis Ababa: Traffic Simulation; Unpublished MA Thesis, Addis Ababa University (AAU), Ethiopia.

18. WHO. (2009). Global Status Report on road safety: Time for action Geneva, World Health Organization. Report.

19. Anthony, Z. (2004). Health Economics and Financing Program, Health Policy Unit, Road traffic injuries in developing countries.

20. Brian, C. (2014). Tefft Prevalence of Motor Vehicle Crashes Involving Drowsy Drivers, United States.

21. Saadat, S., \& Soori, H. (2008). Epidemiology of traffic injuries and motor vehicles utilization in the Capital of Iran.

22. de Almeida, G. C. M., de Medeiros, F. D. C. D., Pinto, L. O., de Oliveira Moura, J. M. B., \& Lima, K. C. (2016). Prevalence and factors associated with traffi c accidents involving motorcycle taxis. Revista brasileira de enfermagem, 69(2), 359.

23. Odiwuor, C. W., Nyamusi, E., \& Odero, W. (2015). Incidence of road traffic crashes and pattern of injuries among commercial motorcyclists in Naivasha Town. Int J App Res, 1(11), 541-549.

24. Osoro, A. A., Ng'ang'a, Z., \& Yitambe, A. (2015). An analysis of the incidence and causes of road traffic accident in Kisii, Central district, Kenya. IOSR Journal Of Pharmacy, 5(9), 41-49.

25. National road safety management framework, 2014.

26. Almaz Berhe, A. C., \& Bayray, A. (2014). Assessment of Road traffic accidents among children in Addis Ababa City, Ethiopia; a retrospective record. Journal of Medical Science and Technology, 3(3), 25-36.

27. Anteneh, K. (2013). Road Traffic Accident related Fatalities in Addis Ababa City, Ethiopia.

28. Asefa, F., Assefa, D., \& Tesfaye, G. (2014). Magnitude of, trends in, and associated factors of road traffic collision in central Ethiopia. BMC public health, 14(1), 1072.

29. Bashah, D. T., Dachew, B. A., \& Tiruneh, B. T. (2015). Prevalence of injury and associated factors among patients visiting the Emergency Departments of Amhara Regional State Referral Hospitals, Ethiopia: a cross-sectional study. BMC emergency medicine, 15(1), 20.

30. Yayeh, A. (2003). The extent, variations and causes of road traffic accidents in Bahir Dar. Addis Ababa university, Ethiopia.

31. Hailemichael, F., Suleiman, M., \& Pauolos, W. (2015). Magnitude and outcomes of road traffic accidents at Hospitals in Wolaita Zone, SNNPR, Ethiopia. BMC research notes, 8(1), 135.

32. Fikadu, M. (2015). Road Traffic Accident: Causes and Control Mechanisms: The Case of Addis Ababa City. 